\title{
Ektopik Gebelikte 0. ve 4. gün $\beta$-HCG Değerleri ile Metotreksat Tedavisinin Başarısı Öngörülebilir mi?*
}

\section{Can $\beta$-HCG Values on day 0 and 4 in Ectopic Pregnancy Predict the Success of Methotrexate Treatment?}

\section{Öz}

Amaç: Ektopik gebelik uterin kavite dışında gelişen gebelikleri tanımlar ve bütün gebeliklerin yaklaşık \%2'sini oluşturur. Maternal mortalitenin \%10'undan sorumludur (1). Ektopik gebeliklerin yaklaşık \%97'si tubada görülmektedir (2). Klasik triadı patognomonik olmamakla birlikte menstruasyon gecikmesi, vajinal kanama ve tek taraflı alt kadran ağrısıdır. Medikal tedavi, cerrahi tedavi veya bekle-gör yöntemi uygulanabilecek yaklaşımlardır. Son yillardaki gelişmeler ektopik gebelik tanısının daha erken aşamada konmasına ve metotreksat tedavisinin yaygınlaşmasına neden olmuştur. Bu retrospektif çalışmada tek doz metotreksat (MTX) tedavisi uygulanan 71 ektopik gebelik olgusunda başarı oranlarımızı, erken dönem $\beta$-HCG değişikliklerini ve bunların tedavinin başarııı üzerindeki etkilerini araşı̧ımayı amaçladık.

Gereç ve Yöntemler. Çalışmada ektopik gebelik tanısı ile yatırılan ve tek doz MTX tedavisi uygulanan 71 hasta retrospektif olarak değerlendirildi. Hastaların 0., 4. ve 7. gün $\beta$-HCG değerleri incelendi. Tedavinin başarılı ve başarısız olduğu gruplar yaş, geçmiş ektopik gebelik öyküsü, geçirilmiş abdominal cerrahi öyküsü, sigara kullanımı, tanı sırasında pelvik kitle, serbest sıvı ve pozitif fetal kardiyak aktivite varlığı açısından karşılaştııııdı. Her grup için 0. ve 4. gün $\beta$-HCG değerlerinde artış ve düşüş gösteren hasta yüzdeleri belirlendi. Dördüncü gün $\beta$-HCG değerlerinde artış saptanan hastalarda $\triangle \mathrm{HCG}$ (fark değişkeni) 4. gün $\beta-H C G$ değeri - 0 . gün $\beta-H C G$ değeri biçiminde hesaplanarak tedavinin başarıı olduğu ve başarısızlıkla sonuçlandığı gruplar karşılaştırıldı.

Bulgular. Tek doz MTX tedavisinin başarı oranı \%66,2 olarak belirlendi. Başarısız tedavi grubunda 0 . ve 4 . gün $\beta-H C G$ değerleri anlamlı olarak daha yüksekti $(p=0,018)$. Tedavinin başarılı olduğu grupta hastaların \%38,7'sinde, başarısızıı ile sonuçlandığı grupta ise \%35,3'ünde 4 . gün $\beta$-HCG değerlerinde artış saptandı. Başarısız tedavi grubunda $\triangle \mathrm{HCG}$ ortalama ve medyan değerleri daha yüksek tespit edilse de fark istatistiksel olarak anlamlı bulunmadı $(p=0,58)$.

Tartışma ve Sonuç: Tek doz MTX tedavisinin başarısı konusunda; yüksek bazal $\beta$-HCG değerlerinin yanı sıra 4. gün $\beta$-HCG değerlerinde artış gözlenen hastalar için yüksek $\triangle H C G$ değeri ile de başarısızlık öngörülebilir.

Anahtar Sözcükler. Ektopik gebelik; $\beta$-HCG; metotreksat

\section{Abstract}

Aim: Ectopic pregnancy describes the pregnancies that develop outside the uterine cavity and composes about $2 \%$ of all pregnancies. It is responsible for approximately $10 \%$ of cases of maternal mortality (1). $97 \%$ of ectopic pregnancies are seen in the tuba (2). The classic, though non-pathognomonic, triad of the condition is delay of menstruation, vaginal bleeding, and unilateral pelvic pain. Medical treatment, surgical treatment, and expectant management can be applied. In recent years our success in diagnosing ectopic pregnancies earlier has led to widespread use of methotrexate treatment. In this retrospective study, we aimed to investigate our success rate in 71 ectopic pregnancy patients who underwent single-dose methotrexate (MTX) treatment, in connection with early period of $\beta-\mathrm{HCG}$ changes and their impact on the success of the treatment.
Nefise Tanrıdan Okcu', Ayşe Topçu Akduman² Bilge Çetinkaya Demir ${ }^{3}$

1 Adana Numune Eğitim ve Araştırma Hastanesi, Kadın Hastalıkları ve Doğum Kliniği, Adana, Türkiye

2 Düzce Atatürk Devlet Hastanes Kadın Hastalıkları ve Doğum Servisi, Düzce, Türkiye

${ }^{3}$ Uludağ Üniversitesi Tıp Fakültesi Hastanesi Kadın Hastalıkları ve Doğum Anabilim Dalı, Bursa, Türkiye
Geliş Tarihi /Received : 04.07.2016 Kabul Tarihi /Accepted: 24.11.2016

DOI: 10.21673/anadoluklin.284474

Sorumlu Yazar/Corresponding Author Nefise Tanridan Okcu

Serinevler Mah. Ege Bağatur Bulvarı Üzeri Yüreğir, Adana, Türkiye

E-mail: nefise-tanridan@hotmail.com 
Materials and Methods: In this retrospective study we evaluated 71 patients who had been diagnosed with ectopic pregnancy and treated with single-dose MTX treatment. We investigated the 0th, 4th, and 7th day $\beta$-HCG values of the patients. The groups in which the treatment had been successful and unsuccessful were compared in terms of age, previous ectopic pregnancy history, cigarette-smoking history, previous abdominal surgery history, and presence of pelvic mass, free liquid, and positive fetal cardiac activity during the diagnosis. The percentages of the patients whose 0 th and 4 th day $\beta$-HCG values showed an increase or decrease were determined in each group. In patients whose 4 th day $\beta-H C G$ values were seen to have increased, $\triangle H C G$ (the difference variable) was calculated as 4th day $\beta-H C G$ value - 0th day $\beta-H C G$ value and a comparison was made between the successful treatment and unsuccessful treatment groups.

Results: The success rate of single-dose MTX treatment was found to be $66.2 \%$. In the group in which MTX treatment was unsuccessful, 0 th and 4 th day $\beta-H C G$ values were statistically significantly higher $(p=0.018)$. The 4 th day $\beta$-HCG values were detected to have increased in $38.7 \%$ of patients in the successful MTX treatment group and $35.3 \%$ of patients in the unsuccessful MTX treatment group. Although the average and median $\triangle H C G$ values were detected to be higher in the unsuccessful MTX treatment group, the difference was not statistically significant $(p=0.58)$.

Discussion and Conclusion: With respect to predicting the success of single-dose MTX treatment, high $\triangle H C G$ values, in addition to high basal $\beta$-HCG values, can also predict unsuccess in patients whose $\beta$-HCG values are observed to have increased on day 4.

Keywords: Ectopic pregnancy; $\beta$-HCG; methotrexate

\section{GíRiş}

Ektopik gebelik uterin kavite dişında gelişen gebelikleri tanımlar ve bütün gebeliklerin yaklaşık \%2'sini oluşturur (1). Ektopik gebelik jinekolojik acillerden biri olup halen ilk trimester morbiditeleri içinde birinci sırada yer almaktadır (2). Maternal mortalitenin \%10'undan sorumludur (3). Ektopik gebeliklerin yaklaşık \%97'si tubada görülmektedir (4). Klasik triadı patognomonik olmamakla birlikte menstruasyon gecikmesi, vajinal kanama ve tek taraflı alt kadran ağrısıdır. Medikal tedavi, cerrahi tedavi veya bekle-gör yöntemi uygulanabilecek yaklaşımlardır. Son yıllardaki gelişmeler ektopik gebelik tanısının daha erken aşamada konmasına ve metotreksat tedavisinin yaygınlaşmasına neden olmuştur. Modern tanı metotlarının yaygınlaşması, ektopik gebeliklerin daha erken aşamada tanılanmasına olanak sağlayarak, bu hastalıkla ilişkili mortalite ve morbidite oranlarının düşmesine neden olmuştur (4). Trofoblastik hücrelerin proliferasyonunu inhibe ederek etki gösteren sistemik metotreksat (MTX) tedavisi, hemodinamik olarak stabil ve kontrendikasyonu bulunmayan hastalarda birinci basamak tedavisi olarak yaygınca kullanılmaktadır. Tek doz veya multidoz metotreksat uygulamalarının başarı oranı \%65-96 arasında bildirilmektedir (5). Tek doz MTX tedavisinin başarısını öngörmede bazal $\beta$-HCG ve progesteron değeri, fetal kardiyak aktivitenin ve yolk kesesinin varlı̆̆ı, ektopik gebelik kesesinin çapı, 0.-4. gün $\beta$-HCG değerlerindeki değişim gibi birden fazla faktör araştırılmıştır (5-8). Bu retrospektif çalış- mada tek doz MTX tedavisi alan hastalarda 0.-4. gün $\beta$-HCG değerlerindeki değişimi ve tedavi başarısı arasındaki olası ilişkiyi incelemeyi amaçladık.

\section{GEREÇ VE YÖNTEMLER}

Çalışmanın amacı MTX tedavisi uygulanan ektopik gebelik tanılı hastalarda $\beta$-HCG 0 . ve 4 . gün değerlerinde yükseliş ya da düşüşün medikal tedavi başarısına etkisi olup olmadığının belirlenmesiydi. Çalışma için etik kurul onayı 15 Ağustos 2013 tarihinde alındı. Uludağ Üniversitesi Kadın Hastalıkları ve Doğum Kliniğinnde Ocak 2008 - Ocak 2012 tarihleri arasında ektopik gebelik tanısı ile yatırılan ve tek doz MTX tedavisi almış olan toplam 71 hastanın kayıtları retrospektif olarak değerlendirildi. Ektopik gebelik tanısı;

- Serum $\beta$-HCG değerlerinin $1500 \mathrm{mIU} / \mathrm{ml}$ üstünde olması ve transvajinal ultrasonografide intrauterin gebelik kesesinin gösterilememesi,

- $1500 \mathrm{mIU} / \mathrm{ml}$ altındaki değerlerde $\beta$-HCG'nin 48 saatte \%60'dan az artı̧ göstermesi veya plato çizmesi ile dilatasyon küretaj (D/C) sonucunda yapılan patolojik incelemede koryonik villüs saptanmaması

- Ve/veya küretaj sonrasında $\beta$-HCG değerlerinin plato çizmesi ile kondu.

Metotreksat tedavisi almış olan 71 hastanın kayıtlarına ulaşılabildi. MTX tedavisi için hemodinamik instabilite, aktif hepatik veya renal hastalık kesin kontrendikasyon; $\beta$-HCG değerinin $10.000 \mathrm{mIU} / \mathrm{ml}$ üstün- 
Tablo 1. Grupların demografik özellikleri

\begin{tabular}{|c|c|c|c|}
\hline Değişkenler & Başarı & Başarısızlık & $p$ \\
\hline Yaș (ortalama) & $28,42 \pm 6,38$ & $31,82 \pm 4,56$ & $0,49^{* *}$ \\
\hline Ektopik gebelik öyküsü & $6 / 47(\% 12,7)$ & $3 / 24(\% 12,0)$ & $0,64^{*}$ \\
\hline Abdominal cerrahi öyküsü & $16 / 47(\% 34)$ & $12 / 24(\% 52,9)$ & $0,19^{*}$ \\
\hline Sigara & $7 / 47(\% 16,1)$ & $5 / 24(\% 23,5)$ & $0,39^{*}$ \\
\hline TV-USG kitle & $14 / 47(\% 29)$ & $11 / 24(\% 47,1)$ & $0,17^{*}$ \\
\hline TV-USG sivı & $21 / 47(\% 45,2)$ & $9 / 24(\% 41,2)$ & $0,52^{*}$ \\
\hline FKA pozitifliği & $3 / 47(\% 6,2)$ & $2 / 24(\% 8)$ & $0,28^{*}$ \\
\hline
\end{tabular}

de olması ve pozitif fetal kardiyak aktivitenin olması rölatif kontrendikasyon olarak kabul edildi. MTX tek doz $50 \mathrm{mg} / \mathrm{m}^{2}$ olarak intramüsküler yolla uygulandı. Dördüncü ve yedinci günler arasında $\beta$-HCG değerlerinde \%15 düşüş olması ve haftalık takiplerinde bu düşüşün progresif olarak devam ederek serum $\beta$-HCG değerlerinin $5 \mathrm{mIU} / \mathrm{ml}$ altına inmesi durumunda tedavi başarılı olarak kabul edildi. İkinci doz MTX tedavisine veya cerrahiye ihtiyaç duyulan hastalarda ise tedavi başarısız olarak kabul edildi. Dördüncü gün $\beta$-HCG değerlerinde artış olan hastalar için HCG fark değişkeni $(\Delta \mathrm{HCG}=4$. gün $\beta$-HCG değeri -0 . gün $\beta$-HCG değeri formülü ile) hesapland.

\section{İstatistiksel Analiz}

Kategorik değişkenlerin analizinde Fisher's exact test, sürekli değişkenler için Student's t-test kullanıldı ve $\mathrm{p}<0,05$ anlamlı kabul edildi.

\section{BULGULAR}

Tek doz MTX tedavisi $47(\% 66,2)$ hastada başarılı olurken, $9(\% 12,6)$ hastada ikinci doz MTX tedavisi, $15(\% 21,1)$ hastada cerrahi uyguland. Yirmi dört $(\% 33,79)$ hastada ikinci doz MTX tedavisine veya cerrahi tedaviye ihtiyaç duyuldu. Tedavinin başarı ve başarısızlıkla sonuçlandığı gruplar arasında yaş, sigara kullanımı, geçirilmiş abdominal cerrahi öyküsü, geçmiş ektopik gebelik öyküsü, tanı sırasında adneksiyal kitle, intraperitoneal sıvı ve fetal kardiyak aktivite varlığı açısından fark saptanmadı (Tablo 1).

Tedavinin başarılı olduğu grupta 29/47 (\%61,3) hastada, tedavinin başarısızlıkla sonuçlandığı grupta ise $15 / 24(\% 64,7)$ hastada 4 . gün $\beta$-HCG değerinde düşüş gözlendi. Gruplar arasındaki fark anlamlı değildi (Fisher's exact test-0,53). Sifırınc1 ve 4. gün $\beta$-HCG değerleri başarısız tedavi grubunda anlamlı olarak daha yüksekti $(\mathrm{p}=0,018)$. Toplam 27/71 (\%38) hastada 4. gün $\beta$-HCG değerlerinde artış gözlendi. Bu gruptaki her hasta için fark değişkeni $\Delta \mathrm{HCG}=4$. gün $\beta-\mathrm{HCG}$ değeri - 0. gün $\beta$-HCG değeri formülüyle hesaplandı. Tedavinin başarısız olduğu grupta $\Delta \mathrm{HCG}$ ortalama ve medyan değerleri daha yüksek tespit edilse de gruplar arasındaki fark istatistiksel olarak anlamlı bulunmadı $(\mathrm{p}=0,58)($ Şekil 1 $)$.

\section{TARTIŞMA}

Ektopik gebelik tedavisinde bekle-gör yöntemi, medikal ve cerrahi tedavi gibi farklı yaklaşımlar vardır. Günümüzde bu yaklaşımlar kabul görse de, hastanın bulgularını ve fertilitesini göz önünde bulundurarak hastanın durumuna özel tercih yapılması önerilmektedir. Bu çalışmada tek doz MTX enjeksiyonu uygulanan hastalarda serum $\beta$-HCG seviyelerinde 0 . gün ve 4. gün arasındaki düşüş ile tedavi başarısının öngörülüp öngörülemeyeceği değerlendirildi.

Kliniğimizin son dört yllının verilerini kapsayan bu retrospektif çalsşmada, tek doz metotreksat tedavisi uygulamasında başarı oranı \%66,2 olarak saptandı. $\mathrm{Bu}$ oran literatürde bildirilen \%65-96 başarı oranı ile uyumludur (5). Tedavinin başarılı olduğu grupta hastaların \%61,4'ünde, başarısız olduğu grupta ise \%64,2'sinde 4. gün $\beta$-HCG değerlerinde düşüş gözlendi.

Skubisz ve ark. 45 ektopik gebelik tanılı hastada yaptıkları retrospektif çalışmada, cerrahi müdahale ve ek doz gerekmeden tek doz MTX tedavisi ile başarı 
Şekil 1. $\Delta$ HCG Medyan Değerleri

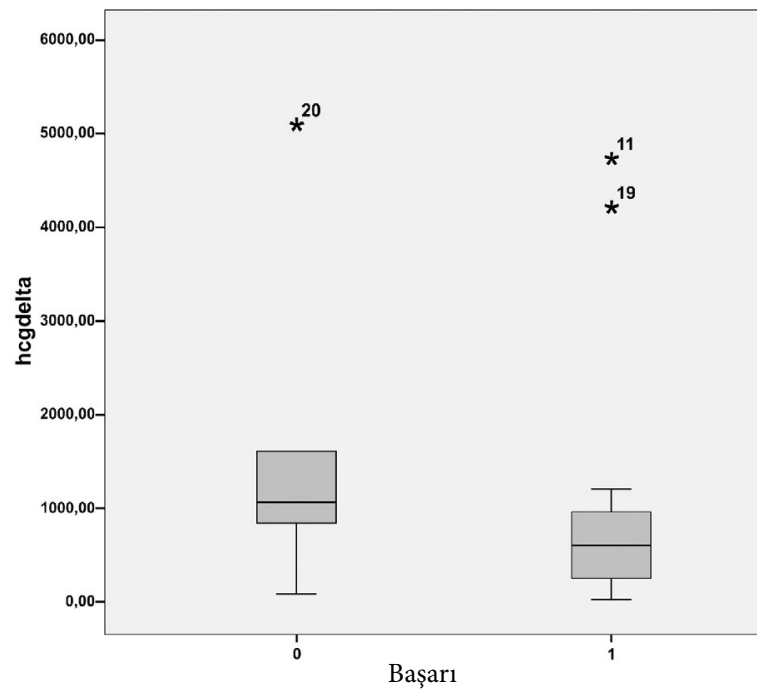

0-Tedavi Başarısızlı̆̆ı, 1-Başarılı Tedavi

oranını \%88 olarak bildirmiştir. Başarılı tedavi grubunda hastaların \%42'sinde 4. gün $\beta$-HCG artışı izlenmiştir (9). Bu çalışmada da başarılı tedavi grubunda hastaların \%39'unda 4. gün $\beta$-HCG artışı izlenmiştir. Nguyen ve ark. tarafından, tek doz MTX tedavisi alan 30 ektopik gebelik hastası ile yapılan retrospektif bir çalışmada tedavinin başarılı olduğu grupta hastaların tümünde (\%100) 4. gün $\beta$-HCG değerinde düşüş tespit edilmiştir (10). Bizim çalışmamızda bu başarı oranına ulaşılamadı. Çalışma sonuçlarımız, ektopik gebelik rezolüsyonuna kadar $\beta$-HCG’nin haftalık olarak takibine devam edilmesi gerektiğini göstermektedir. Agostini ve ark. tarafından yapılan çalışmada ise 1. gün ve 4 . gün $\beta$-HCG değerleri arasında $\geq \% 20$ düşüş olması durumunda başarılı olma olasılı̆̆ $\% 97$ bulunmuştur (11). Fakat bu çalışmada birden fazla kez MTX uygulanmış olması başarısızlık olarak kabul edilmemiştir ve sonuçların olduğundan yüksek bulunmasına yol açmıștır.

Natale ve ark. çalışmasında ise tek doz MTX alan 58 hastadan 30'unda 3. gün $\beta$-HCG değerlerinde düşüş saptarken, 9 hastada artış gözlenmiştir. MTX tedavisinden sonraki erken dönem $\beta$-HCG artışlarının, tedaviye farklı yanıt veren grupların varlığını gösteren ve daha fazla araştırılması gereken bir fenomen olduğu sonucuna varılmıştır (12).

Daha önce birden fazla çalışmada gösterilen yüksek bazal $\beta$-HCG değeri ve başarısız MTX tedavisi arasındaki ilişki bu çalışmada da gösterildi $(13,14)$. Teda- vinin başarısız olduğu grupta bazal ve 4 . gün $\beta$-HCG değerleri anlamlı olarak daha yüksek tespit edildi.

Bazal $\beta$-HCG değerine ilave olarak, MTX uygulamasından sonra 4. gün $\beta$-HCG değerlerinde artış gözlenen hastalarda $\triangle \mathrm{HCG}$ değeri de başarısız tedavi grubunda istatistiksel anlamlılığa ulaşmamakla birlikte daha yüksek bulundu. Bazal ve $\Delta$ HCG değerleri implantasyonda daha başarıll, daha ileri gebelik haftasında olan ve iyi gelişen ektopik gebeliğin özelliklerinin yansımaları olarak kabul edilebilir. Böyle bir gebeliğin MTX tedavisinden etkilenme olasılığı, daha kötü implantasyon gösteren ve daha az trofoblastik doku içeren ektopik gebeliklere göre daha düşük olacaktır. $\triangle$ HCG değeri de MTX etkilerine rağmen büyümeye devam eden ektopik trofoblastik dokuların göstergesi ve tedaviye yanıtın prediktörlerinden biri olarak klinik pratikte kullanılabilir, ancak klinik değeri daha geniş prospektif çalışmalarla desteklenmelidir.

\section{SONUÇ}

Yüksek bazal $\beta$-HCG değerlerinin yanı sıra, 4. gün $\beta$-HCG seviyelerinde artış gözlenen hastalarda yüksek $\triangle$ HCG değeri ile de tek doz MTX tedavisinde başarısızlık öngörülebilir.

\section{KAYNAKLAR}

1. Lozeau AM, Potter B. Diagnosis and management of ectopic pregnancy. Am Fam Physician. 2005; 72(9):170714.

2. Chang J, Elem-Evans LD, Berg CJ, et al. Pregnancy-related mortality surveillance: United States, 1991-1999. MMWR. 2003;52(SS02):1-8.

3. Gibbs R, Karlan B, Haney A. Danforth's Obstetrics and Gynecology. Baltimore: Lippincott Williams and Wilkins; 2010.

4. Hajenius PJ, Mol F, Mol BW, Bossuyt PM, Ankum WM, Van der Veen F. Interventions for tubal ectopic pregnancy. Cochrane Database Syst Rev. 2007;(1):CD000324.

5. Barnhart KT, Gosman G, Ashby R, Sammel M. The medical management of ectopic pregnancy: a metanalysis comparing "single-dose" and "multidose" regimens. Obstet Gynecol. 2003;101(4):778-84.

6. Gabbur N, Sherer DM, Hellmann M, Abdelmalek E, Phillip P, Abulafia O. Do serum beta-human chorionic gonadotropin levels on day 4 following MTX treatment of patients with ectopic pregnancy predict successful single dose therapy? Am J Perinatol. 2006;23(3):193-6. 
7. Lipscomb GH, Gomez IG, Givens VM, Meyer NL, Bran DF. Yolk sac on transvaginal ultrasound as a prognostic indicator in the treatment of ectopic pregnancy with single-dose methotrexate. Am J Obstet Gynecol. 2009;200(3):338.e1-e4.

8. The Practice Committee of the American Society for Reproductive Medicine. Medical treatment of ectopic pregnancy. Fertil Steril. 2008;90(5):206-12.

9. Skubisz M, Lee J, Wallace E, Tong S. Decline in $\beta$ hCG levels between days 0 and 4 after a single dose of methotrexate for ectopic pregnancy predicts treatment success: a retrospective cohort study. BJOG. 2011;118(3):1665-8.

10. Nguyen Q, Kapitz M, Downes K, Silva C. Are early human chorionic gonadotropin levels after methotrexate therapy a predictor of response in ectopic pregnancy? Am J Obstet Gynecol. 2010;202(6):630.e1-5.

11. Agostini A, Blanc K, Ronda I, Romain F, Capelle M, Blanc B. Prognostic value of human chorionic gonadotropin changes after methotrexate injection for ectopic pregnancy. Fertil Steril. 2007;88(2):504-6.
12. Natale A, Busacca M, Candiani M, Gruft L, Izzo S, Felicetta I, et al. Human chorionic gonadotropin patterns after a single dose of methotrexate for ectopic pregnancy. Eur J Obstet Gynecol Reprod Biol. 2002;100(2): 227-30.

13. Menon S, Colins J, Barnhart KT. Establishing a human chorionic gonadotropin cutoff to guide methotrexate treatment of ectopic pregnancy: a systematic review. Fertil Steril. 2007;87(3):481-4.

14. Nowak-Markwitz E, Michalak M, Olejnik M, Spaczynski M. Cut-off value of human chorionic gonadotropin in relation to the number of methotrexate cycles in the successful treatment of ectopic pregnancy. Fertil Steril. 2009;92(4):1203-7. 